\title{
O programa Mundo da Leitura e a formação do telespectador infantil e juvenil
}

Paulo Becker"

\section{Resumo}

A pesquisa aborda a recepção do programa televisivo infantil Mundo da Leitura, produzido e exibido semanalmente pelo canal de televisão da Universidade de Passo Fundo, desde o ano de 2003, e retransmitido, em nível nacional, pelo Canal Futura, desde o ano de 2005. São aferidos dados como idade, sexo e naturalidade dos telespectadores, e estudada a relação dos telespectadores com os personagens e os quadros do programa, e, ainda as influências que o programa exerce sobre seus hábitos e preferências de leitura. Os dados foram obtidos por meio da tabulação e da análise de 1035 mensagens eletrônicas enviadas por telespectadores ao programa ao longo do mês de maio de 2012.

Palavras-chave: Programa infantil Mundo da Leitura. Programa educativo de televisão. Formação do leitor. Arte e mídia.
A televisão, desde seu surgimento, foi incorporada pelas sociedades, tornando-se o fenômeno de comunicação de massa de maior audiência dos últimos tempos. Mesmo com a chegada do computador, da internet e dos games, ela é ainda a mídia mais consumida. Especialmente no Brasil, atinge um número significativo de telespectadores com grande ênfase para o público infantil. Segundo pesquisas realizadas pelo Ibope (Instituto Brasileiro de Opinião Pública e Estatística), em 2011, crianças e pré-adolescentes com até 11 anos passavam em torno de 5 horas diárias em frente ao aparelho televisivo. Esse comportamento tem suscitado opiniões contrárias e favoráveis, no entanto, a presença da televisão nos lares brasileiros é definitiva e indiscutível.

Os alunos, antes mesmo de chegarem à escola, já estão familiarizados com a

Professor Doutor do Programa de Pós-Graduação em Letras da Universidade de Passo Fundo. E-mail: paulobecker@via-rs.net

Data de submissão: mar. 2015 - Data de aceite: maio 2015 http://dx.doi.org/10.5335/rdes.v11i1.4965 
linguagem audiovisual, desafiando os educadores a pensar novas estratégias para desenvolverem suas atividades pedagógicas. Em entrevista à revista Nova Escola, edição de março de 2007, Rivoltella ressalta que "Uma das maiores características desse público é o que chamamos de uma disposição multitarefa. Ele responde às mensagens do celular, ouve música no iPod, vê TV e fala com os amigos no Messenger - tudo ao mesmo tempo". As evidências comportamentais de crianças e jovens demonstram a complexidade das ações que praticam com a maior naturalidade. Nesse contexto, a escola dever proporcionar um espaço para que alunos e professores utilizem as mídias e reflitam sobre seus conteúdos, entendendo a necessidade de educar com e para os meios de comunicação. A televisão apresenta um vasto repertório de imagens e informações que interferem diretamente em nosso modo de pensar e agir, e os alunos precisam estar preparados para interpretar os símbolos da sua cultura recebendo o auxílio de seus professores. Ferrés aborda essa questão tecendo alguns questionamentos:

Quais os símbolos que a escola ajuda a interpretar hoje? Os símbolos de que cultura? Se educar exige a preparação dos cidadãos para uma integração reflexiva e crítica na sociedade, como serão integrados cidadãos que não estiverem preparados para realizar de forma crítica aquela atividade à qual dedicam a maioria de seu tempo? [...] Dedica-se muito mais tempo a ensinar a ler do que será depois dedicado à leitura. Dedica-se muito mais tempo a ensinar arte do que será dedicado depois a contemplar a arte. No entanto, a televisão, que se tornou o fenômeno cultural mais impressionante da história da humanidade, é a prática para a qual os cidadãos estão menos preparados (FERRÉS, 1996, p. 9).
A televisão ocasionou a aparição de novas formas de aprendizagem na vida dos alunos e descentralizou os meios de aquisição da informação, oferecendo-lhes outros modos de ver o mundo, de pensar as relações advindas da avalanche de informações a que estão submetidos e de apropriarem-se dos conteúdos que lhes interessam no processo de construção de sua cidadania. Mesmo com a proliferação de sons e imagens, formas e cores que seduzem os sentidos, cativando o telespectador, a mediação da família e da escola é fundamental para que a criança perceba e assimile seus conteúdos de maneira ativa. Para Lazar (1999, p. 103),

[...] o jovem telespectador tem na televisão uma fonte de prazer e diversão, também é verdade que procura ali respostas para as questões que faz sobre o mundo que o rodeia.

Nesse sentido, a produção cultural para o público infantil e juvenil, nos meios midiáticos, requer uma compreensão sobre o repertório infantil de brincadeiras, de espaços de lazer, a forma como crianças pensam, agem e se relacionam com seu meio. Esse público específico tem uma enorme capacidade de absorver e incorporar as novas mídias em suas práticas sociais, seja pela linguagem informatizada, televisiva ou pelos games que dialogam com seu ritmo, seu idioma, e sua sonoridade.

Dessa forma, ainda que o livro (didático ou ficcional) por si só ocupe uma posição respeitável e insubstituível na produção de conhecimento, é imprescindível que o professor o utilize estabelecendo pontes com as novas tecnologias audiovisuais, abrindo novos 
caminhos para a aprendizagem: "Os meios de comunicação, quando usados para a educação podem propor, provocar e mesmo exigir movimentos de alunos e professores" (SADEK, 1999, p. 14). Esses meios podem ser (e cada vez mais são) iniciadores de movimentos. São pontos de partida no processo de educação. Em relação ao conteúdo apresentado pelos meios de comunicação, o autor salienta que as mensagens veiculadas não são recebidas igualmente por todos os alunos. A recepção depende da experiência anterior de cada um e de sua bagagem social e cultural. Assim, pode-se dizer que a mensagem depende muito mais do receptor, que deve estar preparado para receber e decodificar de forma crítica e seletiva o que lhe é apresentado na tela, do que do emissor. Nesse sentido, devemos entender que a comunicação não acontece no vazio. Ela ocorre dentro de um contexto social, dentro de uma realidade cultural que confere significado e valor no processo como um todo. O professor, sendo um mediador dos meios de comunicação e também um ser cultural, realiza suas ações mediadoras a partir de seus próprios referenciais. Sadek fundamenta essa questão ao afirmar que:

O professor-emissor, possuidor de alguns conhecimentos, aptidões [...] organiza e codifica alguns conteúdos, de acordo com uma tradição cultural correspondente ao seu meio, levando em consideração as características do meio de comunicação que utilizará na apresentação (no espaço e/ou no tempo) desses conhecimentos: uma vez emitidos e transmitidos pelo canal escolhido, esses conteúdos serão percebidos e decodificados também a partir de sua cultura - pelo aluno receptor, que os avalia e os incorpora ou não a seu repertório (SADEK, 1999, p. 62).
Dessa maneira, ao desenvolver os conteúdos pedagógicos, o professor escolhe os programas que serão veiculados em sala de aula levando em consideração seus referenciais culturais, os quais, juntamente com o material selecionado, irão ao encontro do "aluno-receptor", que, por sua vez, produzirá significados de acordo com sua bagagem cultural. Segundo Penteado (1991), a TV desafia a escola a explorar o potencial dos programas selecionados para serem apresentados aos alunos, valorizando o prazer na aprendizagem do aluno.

Muitos educadores, pais e críticos da mídia culpam a televisão por moldar e influenciar negativamente o comportamento do público infantil, suscitando o consumo e a violência. É sabido que a programação televisiva, em sua maioria, carece de uma proposta que dialogue com a cultura nacional, difundindo valores que respeitem o cidadão em toda a sua complexidade social. Ao observamos os conteúdos transmitidos por alguns programas, é possível perceber a falta de comprometimento ético, cultural e educacional. Segundo Duarte (2008), a busca constante e desmedida pela audiência está levando as emissoras de TV à repetição de fórmulas que se perpetuam independentemente da qualidade de suas produções. De outro modo, a concepção dos programas ditos "educativos", que deveriam ser divertidos e interessantes para garantir 0 encantamento, não cumpre seu objetivo.

Diante da importância que as produções culturais infantis e as atividades 
lúdicas, narrativas e estéticas assumem na educação de crianças, por envolverem uma forma de pensamento simbólico e intuitivo que expressa a intensidade do ser criança, é preciso identificar como os elementos relacionados à cultura e à fantasia estão presentes na mídia voltada para o público infantil. Para Belinky (1990), o intelecto e as emoções da criança devem ser desenvolvidos por intermédio de experiências vividas ou imaginadas. Portanto, é possível pensar que a televisão pode proporcionar um espaço para o lúdico, fazendo com que a criança exercite e desenvolva suas emoções, desde que os conteúdos e a forma com que os programas são produzidos estejam a serviço de seu desenvolvimento cognitivo. A definição de Belinky (1990, p. 34) para o ato de educar pode assumir a seguinte forma:

Educar é fornecer os instrumentos intelectuais, morais e éticos necessários às crianças (e ao ser humano em geral) visando a sua integração individual, familiar e social, consciente e responsável [...], é integrar a sua personalidade dentro da sociedade, sem prejuízo do senso crítico; é iniciar o processo de maturação que se prolongará por toda a existência do indivíduo.

$\mathrm{O}$ ensino que instrumentaliza os alunos para as mídias deve capacitar o sujeito a analisar a cultura oferecida pelos meios e a elaborar a sua cultura. Para Beth Carmona, da Midiativa (Centro Brasileiro de Mídia para Crianças e Adolescentes), a TV pode ser uma janela e uma ponte para vários campos da vida, não só transmitindo conteúdos de qualidade e valores éticos, mas também esti- mulando a criança a buscar novas formas de conhecimento. Ela deve ser instigante, despertar a curiosidade da criança, evitar que ela se torne uma espectadora passiva dos acontecimentos. Nesse sentido, com a preocupação de incentivar e valorizar a produção de programas infantis de qualidade, o Midiativa e o Prêmio MídiaQ encomendaram uma pesquisa de mercado em 2004 para o Instituto MultiFocus. A pesquisa realizada com sessenta pais de diferentes classes sociais, solicitando suas opiniões sobre as características de um programa infantil de qualidade, demonstrou que os pais têm consciência da influência que a televisão exerce na formação de seus filhos, seja de maneira positiva ou negativa. Os entrevistados também apresentaram interesse em programas de qualidade que possam ampliar o repertório cultural, gerar valores éticos, curiosidade, senso crítico, entretenimento e informação, contribuindo no processo educativo de seus filhos. Os dados da pesquisa foram sistematizados e amplamente debatidos por profissionais da mídia e da educação, resultando nos dez mandamentos de um programa de qualidade: ser atraente; gerar curiosidade; confirmar valores; ter fantasia; não ser apelativo; gerar identificação; mostrar a realidade; despertar o senso crítico; incentivar a autoestima; preparar para a vida.

A pesquisa referida está repleta de significados relativos às características do que se pensava e, ainda hoje, se pensa de um bom programa televisivo para crianças. Dessa maneira, continua sendo 
uma referência no processo de criação de programas televisivos infantis e provoca reflexões cada vez mais profundas sobre o que está disponível na televisão para o público infantil, convidando professores e pais a participarem do processo de apreciação e da crítica sobre essa produção.

\section{Programa televisivo infantil Mundo da Leitura}

\section{Histórico, definição e características}

Criado em 2003, o programa Mundo da Leitura foi veiculado, primeiramente, na UPFTV em canal por assinatura e, logo após, no mesmo ano, passou a ser retransmitido simultaneamente pela TVE-RS, para todo o Rio Grande do Sul, em canal aberto. Em outubro de 2005, esse programa estreou episódios inéditos no canal Futura, da Fundação Roberto Marinho, em rede nacional. Esta parceria levou o programa para a Globo Internacional, atingindo mais de 100 países de língua portuguesa em canal por assinatura.

Apresentando as características de um programa educativo voltado para público infantil e juvenil, o programa Mundo da Leitura também instiga a curiosidade dos adultos, estimulando pais e professores a se envolverem com seu conteúdo. Aborda a literatura de forma lúdica e faz com que o texto literário dialogue com a linguagem da música, do teatro, do cinema, da dança, das artes plásticas, entre outras.
Produzido pelo Centro de Referência de Literatura e Multimeios - Mundo da Leitura, e pela UPFTV, o programa se efetiva como um dos desdobramentos das Jornadas Literárias de Passo Fundo que, há 30 anos, se consolida numa intensa movimentação cultural e literária coordenada pela prof. Dr. ${ }^{\text {a }}$ Tania M. K. Rösing. O grupo que integra a equipe responsável pela realização da pesquisa, produção e execução do programa é interdisciplinar e representa diferentes áreas do conhecimento. $\mathrm{O}$ roteiro, escrito pelo prof. Paulo Becker, também responsável pela concepção dos personagens e consultoria de conteúdo, define o perfil e a qualidade da programação.

Durante todos esses anos, o programa Mundo da Leitura conquistou muitos prêmios, entre eles: Programa Educativo na Mostra de Televisão Universitária de Salvador (BA), em 2004; três premiações (2004, 2006, 2007) no Gramado Cine Vídeo; e também o prêmio Açorianos de Literatura de Porto-Alegre, em 2004, na categoria de Mídia - Televisão.

Estrutura, personagens e quadros

O programa Mundo da Leitura é semanal, e possui o formato de uma revista eletrônica. Cada episódio do programa tem a duração aproximada de 24 minutos, divididos em três blocos de, aproximadamente, 8 minutos.

Os personagens que integram o programa Mundo da Leitura apresentam diferentes traços de personalidade, permitindo que cada criança se identifique com 
suas características. $\mathrm{O}$ gato Gali-Leu é o âncora do programa, gosta de ler livros e escrever poesias. A gata Borralheira é uma gata de rua que gosta de capoeira e das manifestações da cultura popular. Os gatinhos Alice e Alberto, nascidos em 2010, são os filhotes de Gali-Leu e Borralheira. Alberto tem um ar de cientista e está sempre experimentando novas invenções. Alice envolve o espectador com seu espírito aventureiro e é uma defensora das questões ecológicas.

A Natália e o Mil-Faces são os personagens humanos do programa. A Nati, como é chamada carinhosamente por seus companheiros, é muito inteligente, dedicada aos estudos e gosta de passar informações importantes com suas reportagens que abrangem diferentes áreas do conhecimento. O Mil-Faces representa um artista saltimbanco que, na figura de um palhaço bufão, comanda a oficina e muitas brincadeiras. Os vilões, Reco-reco e Ratazana, representam o eixo do mal. A Ratazana é uma rata malvada, vaidosa e arrogante. Odeia livros e leitores e está sempre tramando planos mirabolantes para destruir o Mundo da Leitura. O Reco-reco é o fiel escudeiro da Ratazana. Ele ainda não sabe ler e apresenta uma gagueira na fala.

Entre os quadros que compõem o programa, estão: "Contando histórias", "Oficina", "Fique esperto" "Com a Pulga atrás da orelha", "Jogo Mundo da Leitura", "Dia de gato", "Parlenda", "Trava-língua", "Poesia", "Cantiga de roda", "Dicas de leitura", "Correspondência"e "Labirinto".
O quadro "Contando histórias" traz narrativas que são apresentadas por meio de diferentes técnicas, como teatro de animação, teatro de imagens, teatro de sombras, entre outras linguagens que se utilizam de elementos cênicos como forma de representação das histórias. Com o objetivo de aproximar o espectador da leitura do texto literário, esse quadro envolve lendas, fábulas e contos que resgatam a literatura clássica e a cultura popular. A diversidade de cores, formas, texturas e efeitos visuais, utilizados na produção dos cenários e personagens, ampliam o olhar do espectador, desenvolvendo o seu senso estético e a imaginação.

O quadro "Oficina" permite que a criança experencie atividades lúdicas por meio da produção criativa de elementos e objetos voltados para a arte, a ciência, a música, o teatro, o cinema, entre outras linguagens que dialogam com o perfil do programa. Apresentado pelo Mil-Faces e por uma criança convidada, essas experiências estimulam a criatividade do espectador a partir de materiais plásticos de diferentes naturezas.

O "Fique Esperto" é um quadro em formato de reportagem. É apresentado pela Natália, que aparece como uma repórter investigadora trazendo para a telinha assuntos curiosos sobre diferentes áreas do conhecimento como: saúde, esporte, arte, história, ciências e muitos outros. Algumas vezes, outros personagens do programa, como o Gali-Leu, o Mil-Faces e o Reco-reco participam das reportagens, tornando-as ainda mais interessantes. 
O quadro "Jogo Mundo da Leitura" é um jogo de perguntas e respostas que é gravado a partir da leitura prévia de uma obra literária. É apresentado pelo gato Gali-Leu e pela Natália, que recebem quatro estudantes convidados, sendo que cada dupla representa uma escola. O objetivo do quadro é divertir, estimulando a curiosidade dos telespectadores em relação aos livros referenciados, envolvendo o ambiente escolar, em que alunos e professores são convidados a participar ativamente do processo da leitura e da discussão das obras.

O quadro "Dia de gato" oportuniza ao telespectador conhecer um pouco mais sobre o universo dos personagens e suas características, por meio de tramas inteligentes e bem humoradas. Os diálogos são divertidos e, ao mesmo tempo, estabelecem um elo com os acontecimentos da vida real, ao abordar valores éticos e conflitos humanos sem ser maniqueísta, moralista ou dogmático. Esse quadro gera a identificação do telespectador, que se familiariza com os personagens e com as situações vivenciadas por esses. A trilha sonora dos personagens é apresentada entre os diálogos, envolvendo o público e sensibilizando-o com a linguagem musical.

O "Labirinto" envolve enigmas matemáticos e adivinhas que são apresentados pelo Mil-Faces e pelo Gali-Leu. O quadro consiste em apresentar enigmas e charadas utilizando o recurso de objetos e imagens gráficas, instigando o raciocínio e o pensamento lógico do telespectador ao tentar descobrir as respostas. $\mathrm{O}$ público ainda tem a possibilidade de enviar e-mails com as possíveis respostas, ampliando a sua participação no programa.

O programete "Com a pulga atrás da orelha" aborda diferentes assuntos que dialogam com os outros quadros do programa por meio de perguntas e alternativas de respostas. As respostas são exibidas após o intervalo do primeiro e do segundo bloco, e são acompanhadas de um pequeno vídeo com informações abrangentes sobre $o$ assunto referido.

Os programetes "Parlendas", "Poesias", "Trava-línguas" e "Cantigas de roda", de maneira lúdica, buscam aproximar as crianças do folclore e da poesia, resgatando a cultura popular por meio de brincadeiras.

Com o programete "Dicas de leitura", o espectador tem a oportunidade de conhecer e diversificar seu repertório cultural, a partir das sugestões de leitura em diferentes suportes como livros, CDs, DVDs, sites, entre outras possibilidades que possam contribuir com o enriquecimento do seu acervo de leitura.

O programete "Correspondência" é apresentado pelo Mil-Faces, Gali-Leu, e em outros momentos pela Natália e Borralheira. É o momento em que os e-mails enviados pelos espectadores são lidos, estabelecendo um canal de comunicação entre o programa e o público.

Observando o conteúdo dos dez mandamentos de um programa infantil de qualidade, e com base nos autores cita- 
dos neste texto, podemos reconhecer o programa Mundo da Leitura como um fomentador de cultura e educação para seus telespectadores.

\section{Recepção do programa Mundo da Leitura pelos telespectadores}

Foram analisadas 1035 mensagens enviadas espontaneamente por telespectadores para o programa, em maio de 2012, o que implica que não houve um questionário padrão preenchido pelos pesquisados. Pelo contrário, foi elaborado um instrumento para recolher dados importantes nas mensagens, mesmo sabendo-se que praticamente nenhuma mensagem traria todos os dados pesquisados.

Quanto à idade dos telespectadores, verificou-se que, entre as crianças que a informam, a maioria (128) encontram-se na faixa etária que o programa pretende preferencialmente atingir, que se situa entre os 5 e 9 anos. Chama a atenção, porém, o número significativo de crianças entre 0 e 5 anos (33 crianças) e acima de 9 anos (74) que também assistem ao programa, o que demonstra que o programa desperta o interesse de uma faixa etária bem mais ampla do que a pretendida ou estabelecida como público-alvo.

$\mathrm{Na}$ grande maioria dos casos, são as próprias crianças que escrevem as mensagens. Entretanto, em 43 casos, são familiares das crianças, em função de essas ainda não estarem alfabetizadas. Esse último dado demonstra que há um comprometimento da família em relação ao que a criança dessa idade acompanha na televisão.

Em relação ao sexo da criança, houve um resultado surpreendente, já que o programa não visa um público de sexo definido. Entretanto, levando-se em conta que $72 \%$ dos telespectadores pesquisados pertencem ao sexo feminino, contra $28 \%$ pertencentes ao sexo masculino, pode-se inferir que o programa desperta interesse maior no público feminino. Uma explicação alternativa para essa grande preponderância do público feminino poderia ser a de que, por algum motivo a ser futuramente pesquisado, as meninas se dispõem mais a escrever mensagens para o programa do que os meninos.

A distribuição do público pelos estados brasileiros demonstra um dado importante: dos 27 estados que compõem a nação, apenas três não possuem mensagens enviadas por telespectadores no período pesquisado, o que demonstra que o programa possui, efetivamente, uma projeção e uma difusão nacionais. Já os números de Minas Gerais e São Paulo se destacam, naturalmente, por serem esses, também, os estados mais populosos do Brasil.

A distribuição do público por regiões do país indica que quase metade dos telespectadores $(47 \%)$ habitam na região Sudeste. Curiosamente, a participação da região Nordeste é muito significativa (27\%), bem superior à participação da região Sul (18\%). Isso demonstra que o fato de o programa ser inteiramente produzido em Passo Fundo, no Rio Gran- 
de do Sul, com elementos linguísticos e culturais próprios de nossa região, não impede que ele tenha boa aceitação nas demais regiões do país.

Apesar de 93\% dos telespectadores não informarem se assistem ao programa na companhia de outros, entre aqueles que informam esse dado é visível que há um compartilhamento da assistência com os pais e irmãos. O compartilhamento com os irmãos, levando-se em conta que a maioria das famílias não tem um filho único, é absolutamente natural e esperável. Já o compartilhamento com os pais é significativo, pois demonstra que os pais, responsáveis diretos pela formação das crianças telespectadoras, aprovam os conteúdos e a proposta do programa.

Tratando-se de uma informação fornecida espontaneamente pelas crianças telespectadoras, é muito significativo que $22 \%$ das crianças manifestem que acompanham o programa sempre, assistindo a todos os episódios veiculados pela televisão. Isso demonstra o alto grau de fidelização do público atingido pelo programa.

Em apenas $21 \%$ dos casos, a criança não especifica a quem está dirigindo a sua mensagem. Na grande maioria dos casos (48\%), ela se dirige à equipe do programa, o que permite perceber que ela distingue que o programa é feito por um coletivo. Já outros 15\% dirigem-se ao Gali-Leu, o gato leitor, mesmo este sendo um boneco, e muitos informam que se identificam com ele porque também gostam de ler; $5 \%$ dirigem-se à
Natália, personagem humana que tem participação especialmente nos quadros do "Jogo", "Dia de Gato" e "Fique Esperto"; 4\% dirigem-se à Borralheira (também um boneco), casada com o Gali-Leu; 4\% dirigem-se ao Mil-Faces, personagem humano com participação especialmente nos quadros da "Oficina", "Dia de Gato" e do "Labirinto". Fica evidente que as crianças que se dirigem a um personagem em particular o fazem por terem uma identificação maior com esse personagem, ou porque o assunto da mensagem induz a isso (por exemplo, dirigir-se ao Mil-Faces para enviar uma sugestão de enigma para o "Labirinto").

A maioria das crianças (59\%) não cita seus quadros preferidos, entretanto entre aquelas que o fazem, o quadro da "Oficina", que ensina a fabricar brinquedos e objetos variados, apresenta um índice destacado de preferência (22\%), o que demonstra o interesse dos telespectadores em aprender a fabricar, eles próprios, diferentes coisas. O "Labirinto", que estimula a resolver adivinhas, problemas lógicos e enigmas, desperta o interesse especial de 7\% dos telespectadores, o que demonstra que o público sente-se estimulado diante de desafios que exigem o uso do raciocínio. Já 5\% dos telespectadores dizem preferir a narração/dramatização de histórias, demonstrando que as narrativas continuam a cativar o público; e 5\% preferem outros quadros que integram o programa. $\mathrm{O}$ resultado baixo relacionado ao quadro "Dia de Gato" deve ser relativizado, uma vez que o nome do quadro não aparece 
em vinheta no início desse, no programa, ao contrário do que ocorre com os outros quadros, e isso impede a criança de identificá-lo. Entretanto, o resultado da questão 13 mostra claramente que $o$ quadro "Dia de Gato" desperta o interesse do público.

Mesmo não sendo estimulados a informarem quais são os seus personagens preferidos no programa, apenas $24 \%$ dos telespectadores não apresentam esse dado. Como era previsível, pelo lugar central que ocupam no programa, o casal de gatos Gali-Leu e Borralheira contam com a preferência maior, respectivamente de $16 \%$ e de $15 \%$ do público - o Gali-Leu por ser um gato leitor, e a Borralheira por ser uma gata que pratica esportes e demonstra muita coragem. Já as personagens humanas Natália e Mil-Faces vêm logo a seguir, tendo a preferência de $14 \%$ e de $12 \%$, respectivamente - a Natália frequentemente associada pelas crianças ao quadro da "História", e o Mil-Faces ao quadro da "Oficina”. Os filhotes Alberto e Alice têm, igualmente, a preferência de $4 \%$ do público, sendo esse número relativamente baixo explicável pela entrada recente desses personagens no programa. Reco-Reco, que é um rato de boa índole, apesar de ficar ao lado da malvada Ratazana, detém também $4 \%$ da preferência. Já a vilã Ratazana, compreensivelmente, é a personagem preferida de apenas $1 \%$ do público, que deve se interessar por ela, provavelmente, não por sua má índole, mas pelos planos mirabolantes que monta para dominar o Mundo da Leitura. Final- mente, $6 \%$ das crianças dizem preferir todos os personagens, indiferentemente, num sinal de que aprovam a proposta do programa como um todo, e entendem o caráter fictício das personagens, sejam elas de boa ou má índole.

Em torno de $2 \%$ das crianças pesquisadas enviaram respostas para o quadro "Labirinto", em relação às adivinhas, enigmas, charadas e problemas lógicos apresentados. A equipe do programa precisará rever o grau de dificuldade das questões propostas, no sentido de estimular e/ou permitir uma participação maior do público.

Significativamente, $11 \%$ das crianças que enviaram mensagens para o programa no período pesquisado apresentam sugestões para o quadro "Labirinto". Esse resultado demonstra o interesse do público em participar mais ativamente do "Labirinto". Assim, mesmo que não consigam responder às questões propostas no programa, ou por isso mesmo, as crianças enviam suas próprias sugestões de adivinhas, charadas e enigmas para a equipe do programa ou para o Mil-Faces.

$\mathrm{O}$ envolvimento das crianças com o quadro "Dia de Gato" fica claro pelos avisos que enviam ao Gali-Leu e demais personagens sobre as maquinações maléficas da Ratazana, em $21 \%$ das mensagens pesquisadas. As crianças buscam auxiliar as personagens do eixo do bem a se protegerem contra os planos da vilã, com os quais, naturalmente, elas não concordam.

Um dos principais motivos para as crianças escreverem para o programa é 
a vontade de enviar beijos, abraços e saudações para as personagens, pelos quais demonstram muito afeto, e isso acontece na metade das mensagens pesquisadas. Também há algumas crianças que enviam beijos, abraços e saudações para seus pais, irmãos, amigos e professores, entre outros, na esperança de verem sua mensagem lida no programa e assistida pelos destinatários das saudações.

Levando-se em conta o caráter espontâneo dessa manifestação dos telespectadores em suas mensagens, é extremamente significativo o reconhecimento, por parte de $13 \%$ dos pesquisados, de que o programa Mundo da Leitura fornece um estímulo a mais para a leitura, além dos que a criança recebe em casa e na escola. Esse dado revela que o principal objetivo do programa está sendo alcançado, e que as próprias crianças que acompanham o programa conseguem identificá-lo e o valorizam de modo indiscutível.

Finalizando, destacamos que as linguagens literária, musical e plástica permeiam todo o programa Mundo da Leitura, desde a produção da trilha musical, a produção do roteiro, das histórias e dos cenários. Todos os elementos presentes nos sons e nas imagens demonstram um cuidado estético em seu conteúdo e sua forma, procurando, acima de tudo, desenvolver em seus espectadores a fruição, a sensibilidade e o pensamento reflexivo sem cair no didatismo ou na carência de conteúdo.
O quadro "Oficina" estimula a criatividade na confecção de brinquedos. As reportagens do quadro "Fique Esperto" envolvem os telespectadores com diferentes áreas, como história, geografia, artes, ciências, esporte, saúde, etc., ampliando seu conhecimento de mundo e preparando-os para o futuro. Os quadros "Contando histórias" e "Dia de gato" geram a identificação do público por apresentarem narrativas e conflitos que fazem parte das suas vivências, estabelecendo uma ponte com a realidade. Numa dinâmica de jogos, brincadeiras e histórias, o programa procura envolver seus telespectadores de uma maneira atraente e divertida, firmando valores éticos e estimulando a fantasia, ao mesmo tempo em que transmite saberes e estimula a formação do pensamento reflexivo e crítico.

\section{The TV show "Mundo $d a$} Leitura" and the nurturing of young viewers

\section{Abstract}

This research addresses the audience's reception of the children's show "Mundo da Leitura", which has been weekly produced and aired by the University of Passo Fundo's television channel since 2003, and broadcast on national television by $\mathrm{Fu}$ tura Channel since 2005. Data such as viewers' age, gender and nationality has been measured, as well as how viewers relate to characters and to program scenes, and also what influence the show has had on their rea- 
ding preferences and habits. The data was obtained through tabbing and the analysis of 1035 electronic messages sent to the show, by viewers, during the month of May, 2012.

Keywords: Children's show "Mundo da Leitura". Educational television show. Reader's nurturing. Art and media.

\section{Referências}

BELINKY, Tatina; GOUVEIA, Julio. Teatro para crianças e adolescentes. A experiência do TESP. In: ZILBERMAN, Regina. A Produção Cultural para a Criança. Porto Alegre: Mercado Aberto, 1990.

DUARTE, Rosália; RUSSO, Kelly; MIGLIORA, Rita; SACRAMENTO, Winston. Escola e mídia: quem tem medo de quê? In: GARCIA, Débora; BRANDÃO, Ana Paula (Org.). Comunicação e Transformação Social: a trajetória do Canal Futura. São Leopoldo, RS: Unisinos - Canal Futura, 2008.

FERRÉS, Joan. Televisão e educação. Porto Alegre: Artes Médicas, 1996.

LAZAR, Judith. Mídia e aprendizagem. In: MINISTÉRIO DA EDUCAÇÃO. Mediatamente! Televisão, cultura e educação. Brasília: Ministério da educação, SEED, 1999.

MARTÍN-BARBERO, Jesús. Heredando el Futuro. Pensar la Educación desde la Comunicación. Nómadas, Bogotá, n. 5, p. 10-22. sept. 1996.

Midiativa. Disponível: <http://www.midiativa.tv/blog/?p=216>. Acesso em: nov. 2011.

Mundo da Leitura. Disponível: <http://mundodaleitura.upf.br/programa/ mundodaleitura/index.html>. Acesso em: 12 nov. 2011.

NOVA ESCOLA. São Paulo: Março, nº. 200, 2007. Disponível em: <http://revistaescola. abril.com.br/formacao/formacao-continuada/ pier-cesare-rivoltella-falta-cultura-digital-sala-aula-609981.shtml>. Acesso em: 22 out. 2011.

PACHECO, Elza Dias. Infância, cotidiano e imaginário no terceiro milênio: dos folguedos infantis à diversão digitalizada. In: PACHECO, E. D. (org). Televisão, criança, imaginário e educação. Campinas: Papirus, 1998.

PENTEADO, Heloísa Dupas. Televisão e escola, conflito ou cooperação? São Paulo: Cortez, 1991.

PORTALSESCSP. Revista e. São Paulo: Fev, n.81, 2004. Disponível em: <http://www. sescsp.org.br/sesc/revistas/revistas_link. cfm?Edicao_Id=179\&Artigo_ID=2698\&IDC ategoria $=2742 \&$ reftype $=2>$. Acesso em: 12 nov. 2011.

PORTAL S4. Disponível: < http://portals4. wordpress.com/2012/01/24/o-brasileiro-nunca-viu-tanta-televisao-ibope-aponta-que-em-2011-passamos-mais-tempo-vendo-tv/>. Acesso em: nov. 2011

SADEK, José Roberto. Educação, movimento e escolha. In: MINISTÉRIO DA EDUCAÇÃO. Mediatamente! - Televisão, Cultura e Educação. Brasília: Ministério da educação, SEED, 1999.

SÁNCHEZ, Francisco Martínez. Os meios de comunicação e a sociedade. In: MINISTÉRIO DA EDUCAÇÃO. Mediatamente! Televisão, cultura e educação. Brasília: Ministério da educação, SEED, 1999. 